\title{
Cost-effectiveness And The Role Of Diagnostic Tools For Screening Early Stages Of Endometrial Cancer
}

Radović S, Potkonjak AM, Knezović Z, Jukić M, Kličan K, Vuković A, Tučkar N, Butorac D, Kuna K. Sestre milosrdnice University Hospital Center Zagreb, Gynecology and obstetrics, Zagreb, Croatia.

\section{Objectives:}

According to the World Cancer Research Fund, over 380,000 new cases of endometrial cancer have been reported in 2018. After the identification of disease, histological diagnosis is standard for managing further treatment approaches. The following analysis is aimed to examine the cost effectiveness of two preoperative endometrial sampling methods comparing localization, grading and staging in patients with endometrial cancer.

\section{Methods:}

The differences in the specifications of 64 patients that underwent hysteroscopy or curettage in tertiary care center in Croatia were tested. According to five different guidelines, all cases of endometrial cancer were classiffed into groups of low risk, intermediate, high intermediate or high risk. Statistical tests used for analysis were Kolmogorov-Smirnov test, Ttest ant the Z-test. Given data of 36 women who underwent hysteroscopy and 28 underwent curettage were analyzed.

\section{Results}

Occurrence rates of grade 1 and grade 2 endometrial cancer were higher in patients who underwent hysteroscopy $(p=0.03572, p=$ 0.03846 respectively) (picture 1 ). No differences according to classification of risk factors were found (picture 2).

\section{Conclusions:}

The cervical dilation and curettage is a lessfrequently used method despite being $62 \%$ more affordable than the hysteroscopy, while on the other hand, there is statistically significant difference in preferred choice of the two methods given the histological grade of cancer and age at the time of diagnosis.

\section{Intermediate and high risk (\%)}

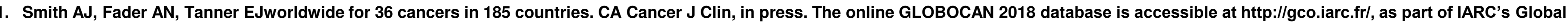
Cancer Observa. Sentinel lymph node assessment in endometrial cancer: a systematic review and meta-analysis. American journal of obstetrics and gynecology. 2017 May 1;216(5):459-76. 2. Morice P, Leary A, Creutzberg C, Abu-Rustum N, Darai E. Endometrial cancer. The Lancet. 2016 Mar 12;387(10023):1094-108. 